\title{
Research on operation of new rural cooperative economic organizations in China
}

\author{
Li Liu \\ School of Marxism, Jilin Agricultural University, Changchun, Jilin 130018, China \\ Liuliu99666@126.com
}

Keywords: new rural cooperative economic organizations, current status, suggestions.

\begin{abstract}
After the reform and opening up, with the development and improvement of Chinese market economic system, the new type of rural cooperative economic organizations emerged which mainly solve the contradictions between farmers and the market and take into account the social and environmental objectives of non-governmental economic organizations with official help. Based on connotation and characteristics of agricultural cooperative economic organization in China, it analyses the problems and causes in the development of agricultural cooperative economic organization and puts up the improvement countermeasures of new rural cooperative economic organizations.
\end{abstract}

\section{Introduction}

Chinese rural cooperative economic organizations was born in the 1940s and 1950s. Its prototype is junior and senior rural cooperative group. Nowadays, its development patterns and purposes are quite different from that in the birth of the cooperative economic organization in the 1990s, so the "new" word is attached into former name. In the 1980s, starting from the farmers ' spontaneous organization of technical service organizations, rural cooperative economic organizations in China have entered a new historical period. During this period, the economic cooperation organization not only in objective, characteristics, but also the nature, functions are quite different from the founding of agricultural cooperatives and the people's commune emerged in 1958. They have been called the new type of rural cooperative economic organizations.

The new development of Chinese rural cooperative economic organization after the founding of new China has deeper causes, namely farmer cooperation has inner certainty. Specifically, after the third plenary session of the 11th Central Committee, China has conducted agricultural and rural economic reforms and the introduction of the household contract responsibility system, farmers' economic status becomes more independent and they also have autonomy in decisions on business, which have greatly aroused farmers' enthusiasm for production. But under the conditions of the socialist market economy, the decentralized management method soon reveals its shortcomings, resulting in a contradiction between "small-scale farmers" with and "market". Because little information can be gained by a single farmer, so the ability to resist natural and market risks is too weak and it is difficult to adapt to the modernization of agriculture [1]. Therefore, farmer organizations is a way to effectively eliminate these drawbacks and internalize the transaction costs and reduce transaction costs to get a richer scale of economies and obtain more accurate information to improve negotiation skills, enhance competitiveness and increase revenue.

Despite many rural cooperation economic organizations exist in China currently, but we also must have the awareness that Chinese rural cooperation economic organization is still in development of primary stage with imperfect development and many matters when compared with earlier developed cooperation economic nations and areas, which seriously hinders new rural cooperation economic organization development. So, taking effective measures to optimize governance structure of Chinese new rural cooperation economic organization has important meaning. 


\section{Concepts of New Rural Cooperative Economic Organizations}

\subsection{Definition and characteristics of New Rural Cooperative Economic Organizations}

New rural cooperation economic organization namely farmer professional cooperation economic organization, which mainly refers to the circulated individuals and organizations engaged in agricultural production and processing emerged in the mid-eighties which under external environment (policy, economy, legal, technology, and social capital, etc) and constraints of itself conditions, based on common interests of production business, it refers to specific economic body through specific cooperation mechanism based on the principle of voluntary participation and mutual benefit [2]. Its subject is the farmers and it runs in accordance with the voluntary, democratic, equal principles and mutual benefit [3]. Since farmer specialized cooperative economic organizations emerged after reform and the organization system is much closer to real cooperation economic organization [4], so it is called new rural cooperative economic organizations.

Chinese current new rural economic cooperative organization mainly occurred in the rural areas, and farmers are participants and it directly serves to the agriculture and upstream and downstream industries. It means that participants are mainly farmers and it serves for farmers and it's an organizational structure to get the most benefit with standard management. Its main features including: first, participation subject are mainly farmers and farmers take part in according to voluntary, equal, mutual benefit principles so it can be called cooperation with many participants. Secondly, the purpose of rural economic cooperation organization is to achieve economic and social target. Farmers will active participate only when the organization can achieve farmers' target. Third, it has standard organization principles and form only in this way, it can fully play farmers' enthusiasm and initiative. Nowadays, from the industrial point of view, new rural economic cooperative organizations is built and developed around the agricultural industry [5].

\subsection{Type of New Rural Cooperative Economic Organizations}

The definition of rural cooperative economic organizations has a variety of ways. It can be roughly concluded into two types:

According to the classified methods of western rural cooperative economic organizations and the procedure of agricultural products from the production to the trade, it is divided into production cooperation economic organization, credit cooperation economic organization, processing cooperation economic organization, supply and marketing cooperative economy organizations, as well as comprehensive cooperation economic organization which are illustrated in Table1.

Table1 Comparison of rural cooperative economic organization classified by purposes

\begin{tabular}{cc}
\hline Type & Purposes \\
\hline Production & Professional production, working efficiency increasing and competition \\
enhancement
\end{tabular}

The second category of rural cooperative economic organization is divided into three main forms namely professional cooperative economy organizations, community organization for economic cooperation and credit cooperation economic organization shown in Fig.1. Fig.2 indicates proportion of those three rural cooperative economic organizations. It shows professional organization overwhelmingly is the principal part of the new type of rural cooperative economic organizations. 


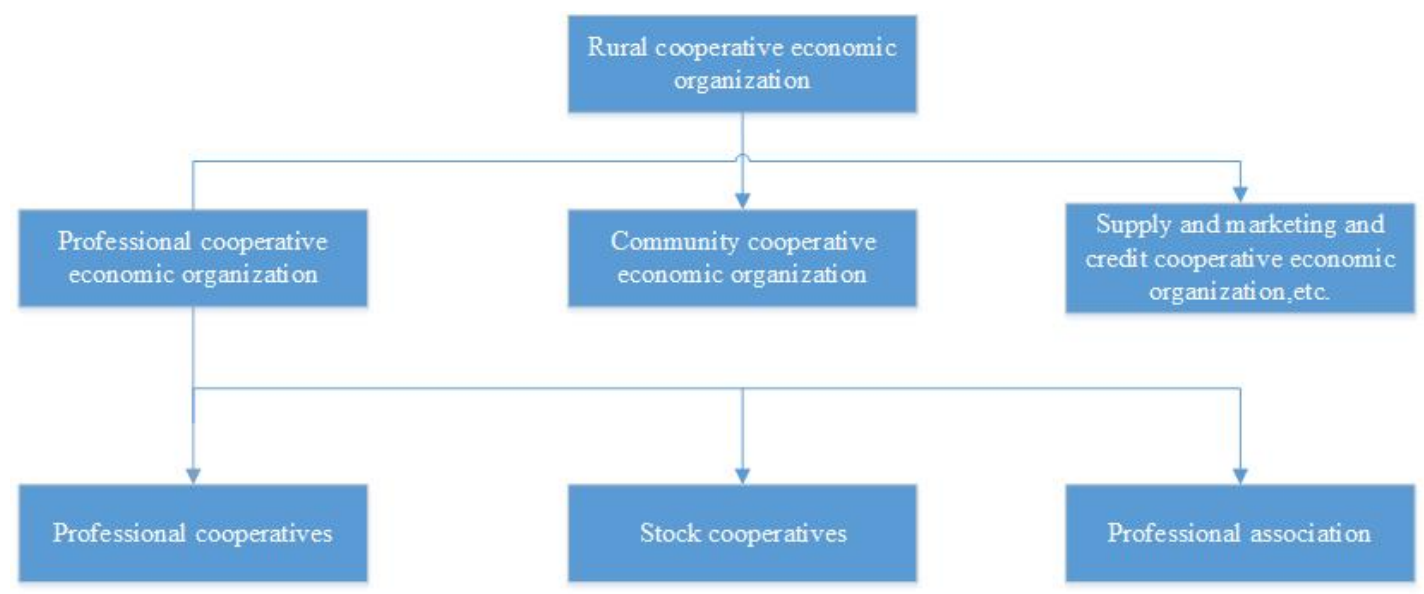

Fig.1 Classification of rural cooperative economic organization

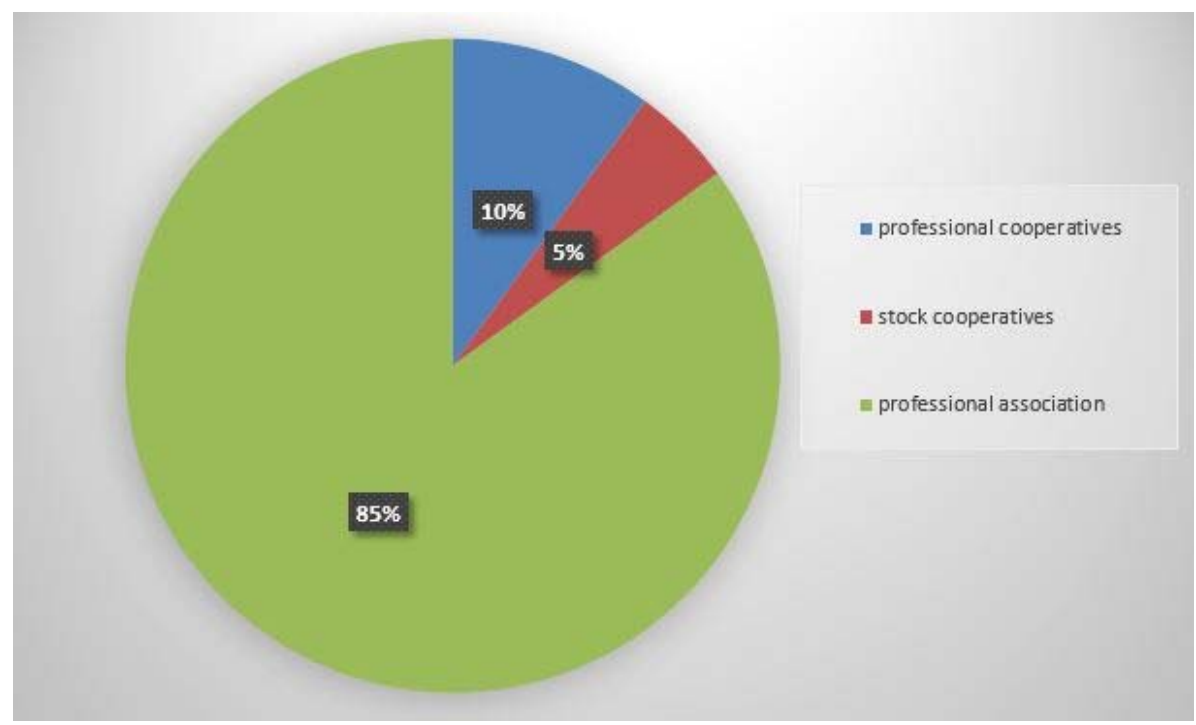

Fig.2 Proportion of three rural cooperative economic organizations

\section{Matters in the Development of Rural Cooperative Economy Organization}

The development of current rural economic cooperation organization have gained the attention of society and it is seen as the important way to improve agricultural production level and economic income. But the current rural economic cooperation organization development is affected by external environment and there are still a lot of shortcomings which need to further improvement. The main problems are shown as follows.

\subsection{Unsound operation mechanism}

Concerning the deficiency of rural economic organization development and nurture malnutrition, it lacks scientific management in organization management operation mechanism. Specifically, rural economic organization affairs decision should reflect the will of farmers. But because of the lower cultural quality, most farmers cannot get better understanding of basic organization and management problems, so the truth is: decision-making power in the economic organization is in the hand of a few people [6].

\subsection{Lack of Financial Support}

Development funds shortage is the important factor causing the delay of its development and seriously restricting the sustainable development of rural economic organizations which reflects on the following aspects:

Small Scale of Financial Support. At present, the cover degree of policy support funds from government to the farmer cooperative economy organization is still small, and it also can't meet the needs of rural cooperative economic organization development. For instance: up to October 2014, the 
total professional cooperatives in Hongan County in Hubei province is 443 and 11 rural professional economic association but in recent three years, the government subsidy funds is only 1.09 million yuan which has a large gap between developed country.

Lack of Coordination and Integration of Support Way. At present, financial support method for cooperative economy organization is money for free of charge but less considers the technical support, a set of financial policy, tax reduction, interest subsidies and other coordination and integration use of support measures. Besides, it lacks the emphasis on the cultivation of members' cooperation consciousness in professional cooperative economic organization, system standardization construction, management level enhancement, personnel training. In terms of its financial policy, the government is still lack of effective guarantee, discount interest and other supporting measures.

\subsection{The Lack of Economic Organization and Management of Human Resources}

As a result of the existence of the education gap between rural and urban areas, the backward of rural education hardware facilities cause students massive outflow to the cities and the return rate is extremely low. Rural young labors also flock to the cities and are engaged in non-agricultural industries rarely interfering with the development of village economic organization, which undoubtedly worsen the already strained economic organization human resources issues. From the beginning of rural economic organizations, it confronts with economic organization talents shortage problems becoming the "short board" of rural economic organization development to severely limit the sustainable development of economic organization.

\subsection{Disordered Economic Organization and Management of Human Resources}

Rural cooperative economy organization lacks normative management. Management mechanism and management ability weakness are the main reasons. The lack of system regulation results in the no use of financial management system, member management system, business management system, interest distribution system, fund accumulation system, democratic decision-making and democratic supervision mechanism hindering the development of it.

\section{Countermeasures for the improvement of Rural Cooperative Economy Organization}

Based on the matters analysis above, the following suggestions have been put up.

\subsection{Standardize the cooperation organization operating mechanism}

In order to ensure healthy and comprehensive development of rural economic cooperation organizations, it is necessary to develop cooperation organization related rules and regulations, clear the rights and obligations as well as the articles of internal associations to make sure the standard working of members in rural economic cooperation organization. Improving work efficiency and protect the interests of the organization are also needed.Secondly, establishing the rural economy internal organization and clearing the function of each department are the way to realize independence and balance between each department.

\subsection{Strong support from government}

Development of agricultural economy has been associated with the Chinese government's strong support. The continued strong support from the government is the foundation guarantee of the sustained development of agricultural cooperation economic organization.Governments must put organizational leadership, propaganda and guidance into practice.Besides the implement of related laws of agricultural cooperation economic organization is another way to make the production and business operation activities of the agricultural cooperation economic organization lawful.

\section{3 Strengthen personnel training, provide intellectual support}

It is necessary to strengthen the education and guidance of farmers, improve their ideological and cultural level, market awareness, competitive awareness, innovative ideas, cooperative awareness and ability to participate in democratic management. It is necessary to strengthen the training of cadres at the grassroots level, change their ideas and improve work leading and guiding development ability. Strengthen the training of the leaders, managers and technical personnel, so they enhance 
their service consciousness, master the market rules and improve the ability of management and technical guidance.

\subsection{Improve the management mechanism to ensure normal operation}

Efficient democratic internal management system is the basis for the efficient operation and healthy development of the new rural cooperative economic organization. The articles of association must include establishment principle, service tenet, conditions, rights and obligations of membership organizations, etc. Refine the management of democracy, capital accumulation, risk aversion, democratic supervision and other aspects in management operating system. The profit distribution system should pay attention to the fair and reasonable principle, rebates and combined with dividends, protection of collective and farmers' income.

\section{Summary}

The development of rural economic cooperation organization is in a critical period. Contradictions in the development of cooperative organizations could be resolved only by strengthening the cooperation organization and strengthening the theoretical guidance of the organization of rural economic cooperation. Establishing the development mode of farmers' interests and promoting the healthy development of Rural Economic Cooperation Organization in view of the current situation of rural economic development in China.

\section{Acknowledgements}

Humanities and Social Sciences project from Ministry of Education: Mechanism Innovation and operation mechanism cooperative economic organizations of Chinese farmers - in Jilin Province (12YJC790118); Social Science Fund Project of Jilin Province: Contemporary Value of Marx and Engels Thought on Cooperative Economy (Project No: 2015M7) series of results.

Liu Li, Associate Professor, School of Marxism, Jilin Agricultural University, he received his $\mathrm{PhD}$ in Jilin University, Master Instructor, research direction: Agricultural Economics and Management.

\section{References}

[1] Gao Lin. Chinese new type of rural cooperative economic organization governance structure research [D]. Jilin:Jilin University, 2014.

[2] Guo Hongdong, Xu Xuchu, Shao Xuewei, et al. The perfection of Chinese rural professional cooperative economy organization development and innovation based on the analysis of practice in Zhejiang Province [J]. China Soft Science, 2004 (12):1-9.

[3] Gui Yu. Governance structure present status and innovation of rural cooperative economy organization [J]. Journal of Henan institute of Engineering (Social\&Science), 2009, (3):24-28.

[4] Gui $\mathrm{Yu}, \mathrm{Xu}$ Wanqiang. Innovation of rural cooperative economy organization governance structure [J]. Frontier, 2009, (12): 49-52.

[5] Ou Jizhong. Chinese new rural economic cooperation organization research in the new period [D]. Wuhan:Wuhan University, 2010.

[6] Yin Yanqiang. Cultivation and perfection of new rural economic organization [J]. China Market. Vol. 818 (2015) No. 3, p. 18-19. 